\title{
Effects of Acrylic Acid on Radical Penetration Length and Conversion in Emulsifier-Free Emulsion Copolymerization of Styrene and Acrylic Acid
}

\author{
Bin-Zw Yang, Leo-Wang Chen, and Wen-Yen ChIU \\ Department of Chemical Engineering, National Taiwan University, \\ Taipei, Taiwan, Republic of China
}

(Received March 4, 1997)

\begin{abstract}
A changeable radical penetration length model is presented in this work for emulsifier-free emulsion copolymerization of styrene and acrylic acid. Radical penetration length in polymer particles varies with the content of acrylic acid. When monomer droplets are present, the radical penetration length is proportional to the number density of polymer particles in solution at the stage of shell region polymerization. However, the radical penetration length keeps constant at this stage in a batch reaction. The $2 / 3$ power of conversion is proportional to the reaction time and $2 / 3$ power of the number density of polymer particles. When the content of acrylic acid is 1.156 to $5.064 \mathrm{gl}^{-1}$ under our experimental conditions, the logarithmic value of the slope obtained from $2 / 3$ power of conversion versus reaction time is proportional to the concentration of acrylic acid in aqueous solution.

KEY WORDS Acrylic Acid / Styrene / Emulsion Copolymerization / Radical Penetration Length / Conversion /
\end{abstract}

The end groups form an initiator anchor on polymer particles in emulsifier-free emulsion polymerization. When polymer particles become large enough, the radicals cannot penetrate the center. The reaction mechanism is shell region polymerization. The relation between the conversion and the reaction time was suggested in many papers under the assumption of constant radical penetration length. ${ }^{1,2}$ When monomer droplets are present in emulsifier-free emulsion polymerization, this relation shows the $2 / 3$ power of conversion is proportional to the reaction time. ${ }^{1,2}$ The slope obtained from $2 / 3$ power of conversion versus reaction time is proportional to the square root of the radical penetration length and $1 / 6$ power of the number density of polymer particles. ${ }^{1,2}$

The radical penetration length varies with the content of comonomer in emulsifier-free emulsion copolymerization of styrene and hydrophilic comonomer. ${ }^{2}$ The constant radical penetration length model does not show how the radical penetration length varies with the content of comonomer. This work explores variation of the radical penetration length. The relations among the radical penetration length, the conversion and the concentration of acrylic acid in aqueous solution in emulsifier-free emulsion copolymerization of styrene and acrylic acid are examined.

\section{THEORETICAL}

\section{Conversion at Shell-Region-Polymerization Stage}

Assume that the radical penetration length, $L$, is proportional to the kinetic chain length in polymer particles and a function of the polymer particle radius at the stage of shell region polymerization in emulsifierfree emulsion copolymerization of styrene and acrylic acid. Let

$$
L=A \cdot f(r) \cdot \frac{k_{\mathrm{p}, \mathrm{p}}[\mathrm{M}]_{\mathrm{p}}}{2 k_{\mathrm{t}, \mathrm{p}}[\mathrm{R} \cdot]_{\mathrm{p}}}
$$

where $A$ is a function of formula and reaction condition, $r$ polymer particle radius, $f(r)$ a function of the radius, $[\mathrm{M}]_{\mathrm{p}}$ and $[\mathrm{R} \cdot]_{\mathrm{p}}$ total concentrations of monomers and radicals in polymer particles, and $k_{\mathrm{p}, \mathrm{p}}$ and $k_{\mathrm{t}, \mathrm{p}}$ overall rate constants of propagation and termination in polymer particles, respectively. Then,

$$
\begin{aligned}
k_{\mathrm{p}, \mathrm{p}}= & \left(k_{\mathrm{ps}}\left[\mathrm{R}_{\mathrm{s}} \cdot\right]_{\mathrm{p}}[\mathrm{S}]_{\mathrm{p}}+k_{\mathrm{psa}}\left[\mathrm{R}_{\mathrm{s}} \cdot\right]_{\mathrm{p}}[\mathrm{AA}]_{\mathrm{p}}+k_{\mathrm{pas}}\left[\mathrm{R}_{\mathrm{aa}} \cdot\right]_{\mathrm{p}}[\mathrm{S}]_{\mathrm{p}}\right. \\
& \left.+k_{\mathrm{paa}}\left[\mathrm{R}_{\mathrm{aa}} \cdot\right]_{\mathrm{p}}[\mathrm{AA}]_{\mathrm{p}}\right) /\left([\mathrm{M}]_{\mathrm{p}}[\mathrm{R} \cdot]_{\mathrm{p}}\right) \\
k_{\mathrm{t}, \mathrm{p}} & =\frac{k_{\mathrm{ts}}\left[\mathrm{R}_{\mathrm{s}} \cdot\right]_{\mathrm{p}}^{2}+k_{\mathrm{tsa}}\left[\mathrm{R}_{\mathrm{s}} \cdot\right]_{\mathrm{p}}\left[\mathrm{R}_{\mathrm{aa}} \cdot\right]_{\mathrm{p}}+k_{\mathrm{taa}}\left[\mathrm{R}_{\mathrm{aa}} \cdot\right]_{\mathrm{p}}^{2}}{[\mathrm{R} \cdot]_{\mathrm{p}}^{2}}
\end{aligned}
$$

where $k_{\mathrm{ps}}$ and $k_{\mathrm{paa}}$ are self-propagation rate constants of styrene and acrylic acid, $k_{\mathrm{psa}}$ and $k_{\mathrm{pas}}$ cross-propagation rate constants between styrene and acrylic acid, $k_{\mathrm{ts}}$ and $k_{\text {taa }}$ self-termination rate constants of styrene and acrylic acid, $k_{\mathrm{tsa}}$ cross-termination rate constant between styrene and acrylic acid, $[\mathrm{S}]_{\mathrm{p}}$ and $[\mathrm{AA}]_{\mathrm{p}}$ concentrations of styrene and acrylic acid in polymer particles, and $\left[\mathrm{R}_{\mathrm{s}} \cdot\right]_{\mathrm{p}}$ and $\left[R_{a a} \cdot\right]_{p}$ concentrations of radicals possessing styrene and acrylic acid at propagating end in polymer particles. Rearrangement of eq 1 yields

$$
[\mathrm{R} \cdot]_{\mathrm{p}}=A \cdot f(r) \cdot \frac{k_{\mathrm{p}, \mathrm{p}}[\mathrm{M}]_{\mathrm{p}}}{2 k_{\mathrm{t}, \mathrm{p}} L}
$$

During shell region polymerization, the radical generation rate, $\rho_{i}$, is equal to the total termination rate in all polymer particles.

$$
\rho_{i}=2 k_{\mathrm{t}, \mathrm{p}}[\mathrm{R} \cdot]_{\mathrm{p}}^{2} \cdot 4 \pi r^{2} L N
$$

where $N$ is the number density of polymer particles in solution and its unit is the number of polymer particles in one liter of aqueous solution. Rearrangement of eq 5 leads to

$$
[\mathrm{R} \cdot]_{\mathrm{p}}=\frac{1}{r}\left(\frac{\rho_{\mathrm{i}}}{8 \pi k_{\mathrm{t}, \mathrm{p}} L N}\right)^{1 / 2}
$$

Comparison of eq 4 and 6 obtains 


$$
\begin{gathered}
f(r)=\frac{1}{r} \\
A \frac{k_{\mathrm{p}, \mathrm{p}}[\mathrm{M}]_{\mathrm{p}}}{2 k_{\mathrm{t}, \mathrm{p}} L}=\left(\frac{\rho_{\mathrm{i}}}{8 \pi k_{\mathrm{t}, \mathrm{p}} L N}\right)^{1 / 2}
\end{gathered}
$$

Rearrangement of eq 8 leads to

$$
L=\frac{2 \pi A^{2}}{\rho_{i}} \frac{k_{\mathrm{p}, \mathrm{p}}^{2}[\mathrm{M}]_{\mathrm{p}}^{2}}{k_{\mathrm{t}, \mathrm{p}}} N
$$

When $L<r$, the polymerization rate at the stage of shell region polymerization is

$$
[\mathrm{M}]_{0} \frac{\mathrm{d} x}{\mathrm{~d} t}=k_{\mathrm{p}, \mathrm{p}}[\mathrm{M}]_{\mathrm{p}}[R \cdot]_{\mathrm{p}} \cdot 4 \pi r^{2} L N
$$

where $x$ is the conversion, $t$ reaction time, and $[\mathrm{M}]_{0}$ total moles of monomers per liter aqueous solution at the beginning of reaction. Combination of eq 5, 9, and 10 yields

$$
[\mathrm{M}]_{0} \frac{\mathrm{d} x}{\mathrm{~d} t}=2 \pi A \frac{k_{\mathrm{p}, \mathrm{p}}^{2}[\mathrm{M}]_{\mathrm{p}}^{2}}{k_{\mathrm{t}, \mathrm{p}}} r N
$$

The relation between conversion, $x$, and polymer particle radius is

$$
\frac{W_{\mathrm{m}} x}{\rho_{\mathrm{p}} N}=\frac{4}{3} \pi r^{3}
$$

where $W_{\mathrm{m}}$ is total weight of monomers per liter aqueous solution at the beginning of reaction, and $\rho_{\mathrm{p}}$ the concentration of polymer swollen by monomers in polymer particles. Insertion of eq 12 into eq 11 lead to

$$
x^{-(1 / 3)} \frac{\mathrm{d} x}{\mathrm{~d} t}=2 \pi A \frac{k_{\mathrm{p}, \mathrm{p}}^{2}[\mathrm{M}]_{\mathrm{p}}^{2}}{[\mathrm{M}]_{\mathrm{o}} k_{\mathrm{t}, \mathrm{p}}}\left(\frac{3 W_{\mathrm{m}}}{4 \pi \rho_{\mathrm{p}}}\right)^{1 / 3} N^{2 / 3}
$$

The concentration of acrylic acid in polymer particles is very low. When monomer droplets are present, the change of the concentration of acrylic acid in polymer particles can be neglected. Therefore, $k_{\mathrm{p}, \mathrm{p}}, k_{\mathrm{t}, \mathrm{p}}, \rho_{\mathrm{p}}$, and $[\mathrm{M}]_{\mathrm{p}}$ are constants in eq 13. If $A$ is independent of reaction time, integration of eq 13 yields

$$
x^{2 / 3}=\frac{4 \pi}{3} A \frac{k_{\mathrm{p}, \mathrm{p}}^{2}[\mathrm{M}]_{\mathrm{p}}^{2}}{[\mathrm{M}]_{0} k_{\mathrm{t}, \mathrm{p}}}\left(\frac{3 W_{\mathrm{m}}}{4 \pi \rho_{\mathrm{p}}}\right)^{1 / 3} N^{2 / 3} t+b
$$

where $b$ is the integration constant.

\section{Effect of Acrylic Acid on the Rate of Polymerization}

Let $\mathrm{S} 1$ represent $\mathrm{d} x^{2 / 3} / \mathrm{d} t$ in eq 13 , thus

$$
S l=\frac{4 \pi}{3} A \frac{k_{\mathrm{p}, \mathrm{p}}^{2}[\mathrm{M}]_{\mathrm{p}}^{2}}{[\mathrm{M}]_{0} k_{\mathrm{t}, \mathrm{p}}}\left(\frac{3 W_{\mathrm{m}}}{4 \pi \rho_{\mathrm{p}}}\right)^{1 / 3} N^{2 / 3}
$$

For the content of acrylic acid at 1.172 to $5.092 \mathrm{~g}$ per liter solution, the number density of polymer particles for various formulas and the relation between $\ln N$ and $[\mathrm{AA}]_{\mathrm{w}}$ was obtained in our previous study. ${ }^{3}$ This relation by recursion is

$$
\ln N=36.00+9.44[\mathrm{AA}]_{\mathrm{w}}
$$

where $[\mathrm{AA}]_{\mathrm{w}}$ is the concentration of acrylic acid in aqueous solution in moles per liter aqueous solution. The fitting curve is shown in Figure 1. The number density values of polymer particles are listed in Table III. When

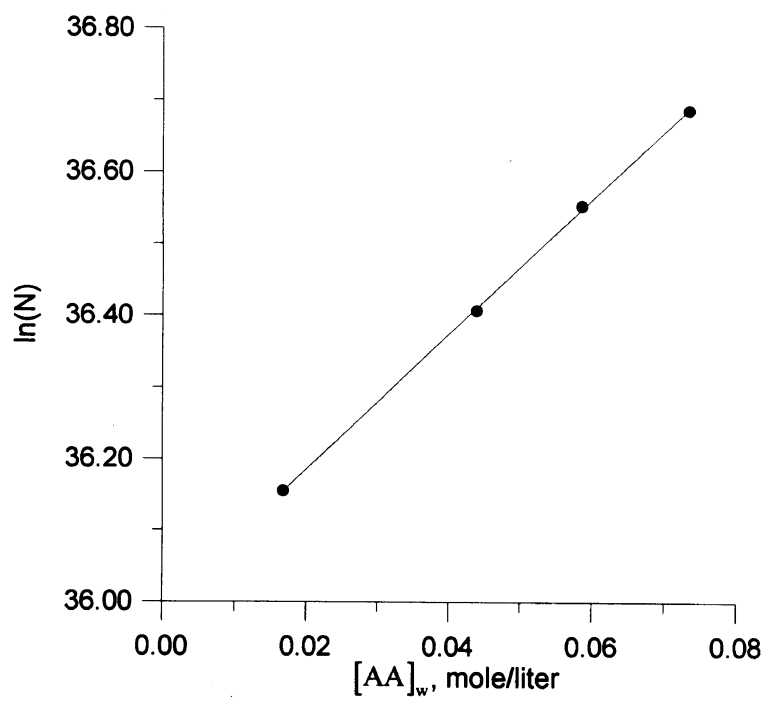

Figure 1. Logarithmic value of number density of polymer particles as a function of concentration of acrylic acid in aqueous solution.

the content of acrylic acid is low, $[\mathrm{M}]_{0}, W_{\mathrm{m}}, k_{\mathrm{p}, \mathrm{p}}$, and $k_{\mathrm{t}, \mathrm{p}}$ can be expressed proportional to $[\mathrm{AA}]_{\mathrm{w}} \cdot[\mathrm{M}]_{0}$ and $W_{\mathrm{m}}$ is written as

$$
\begin{aligned}
{[\mathrm{M}]_{0} } & =[\mathrm{S}]_{0}+[\mathrm{AA}]_{0}=[\mathrm{S}]_{0}\left(1+\frac{[\mathrm{AA}]_{0}}{[\mathrm{~S}]_{0}}\right) \\
W_{\mathrm{m}} & =M_{\mathrm{s}}[\mathrm{S}]_{0}+M_{\mathrm{aa}}[\mathrm{AA}]_{0} \\
& =M_{\mathrm{s}}[\mathrm{S}]_{0}\left(1+\frac{M_{\mathrm{aa}}[\mathrm{AA}]_{0}}{M_{\mathrm{s}}[\mathrm{S}]_{0}}\right)
\end{aligned}
$$

where $[\mathrm{S}]_{0}$ and $[\mathrm{AA}]_{0}$ are moles of styrene and acrylic acid per liter aqueous solution at the beginning of reaction, and $M_{\mathrm{s}}$ and $M_{\mathrm{aa}}$ molecular weights of styrene and acrylic acid, respectively. When $[\mathrm{S}]_{0} \gg[\mathrm{AA}]_{0}$, taking logarithms of eq 17 and 18 leads to

$$
\begin{gathered}
\ln [\mathrm{M}]_{0}=\ln [\mathrm{S}]_{0}+\frac{[\mathrm{AA}]_{0}}{[\mathrm{~S}]_{0}} \\
\ln W_{\mathrm{m}}=\ln \left(M_{\mathrm{s}}[\mathrm{S}]_{0}\right)+\frac{M_{\mathrm{aa}}[\mathrm{AA}]_{0}}{M_{\mathrm{s}}[\mathrm{S}]_{0}}
\end{gathered}
$$

The acrylic acid is distributed between the styrene phase and water phase. The distribution coefficient, $c_{\mathrm{dist}, \mathrm{a}}$, is defined as the ratio of the acrylic acid in one liter of the styrene phase and acrylic acid in one liter of aqueous solution. When $W_{\mathrm{aa}}, W_{\mathrm{s}}$, and $W_{\mathrm{w}}$ represent the weights of acrylic acid, styrene phase and aqueous solution, the amount of acrylic acid in aqueous solution, $W_{\text {aa,w }}$, is

$$
W_{\mathrm{aa}, \mathrm{w}}=\frac{W_{\mathrm{aa}}}{1+c_{\mathrm{dist}, \mathrm{a}} \frac{W_{\mathrm{s}} / \rho_{\mathrm{s}}}{W_{\mathrm{w}} / \rho_{\mathrm{w}}}}
$$

where $\rho_{\mathrm{s}}$ and $\rho_{\mathrm{w}}$ are the densities of the styrene phase and aqueous solution, respectively. The concentration of acrylic acid in aqueous solution is

$$
[\mathrm{AA}]_{\mathrm{w}}=\frac{W_{\mathrm{aa}, \mathrm{w}} / M_{\mathrm{aa}}}{W_{\mathrm{w}} / \rho_{\mathrm{w}}}=\frac{W_{\mathrm{aa}} / M_{\mathrm{aa}}}{W_{\mathrm{w}} / \rho_{\mathrm{w}}+c_{\mathrm{dist}, \mathrm{a}} W_{\mathrm{s}} / \rho_{\mathrm{s}}}
$$

Because $M_{\mathrm{aa}}[\mathrm{AA}]_{0}=W_{\mathrm{aa}} /\left(W_{\mathrm{w}} / \rho_{\mathrm{w}}\right)$, eq 22 is rewritten as 


$$
[\mathrm{AA}]_{0}=\left(1+c_{\text {dist, }} \frac{W_{\mathrm{s}}}{W_{\mathrm{w}}} \frac{\rho_{\mathrm{w}}}{\rho_{\mathrm{s}}}\right)[\mathrm{AA}]_{\mathrm{w}}
$$

Although the amount of acrylic acid is very small in polymer particles, the overall kinetic rate constants change with the concentration of acrylic acid. With the steady-state assumption,

$$
k_{\mathrm{psa}}\left[\mathrm{R}_{\mathrm{s}} \cdot\right]_{\mathrm{p}}[\mathrm{AA}]_{\mathrm{p}}=k_{\mathrm{pas}}\left[\mathrm{R}_{\mathrm{aa}} \cdot\right]_{\mathrm{p}}[\mathrm{S}]_{\mathrm{p}}
$$

Thus, $k_{\mathrm{p}, \mathrm{p}}$ and $k_{\mathrm{t}, \mathrm{p}}$ in eq 2 and 3 are rewritten as

$$
\begin{aligned}
k_{\mathrm{p}, \mathrm{p}}=\frac{k_{\mathrm{ps}}\left[\mathrm{R} \mathrm{s}_{\mathrm{p}} \cdot\right]_{\mathrm{p}}[\mathrm{S}]_{\mathrm{p}}}{[\mathrm{M}]_{\mathrm{p}}[\mathrm{R} \cdot]_{\mathrm{p}}} & \left.\quad \times 1+\frac{2}{r_{\mathrm{s}}} \frac{[\mathrm{AA}]_{\mathrm{p}}}{[\mathrm{S}]_{\mathrm{p}}}+\frac{r_{\mathrm{a}}}{r_{\mathrm{s}}}\left(\frac{[\mathrm{AA}]_{\mathrm{p}}}{[\mathrm{S}]_{\mathrm{p}}}\right)^{2}\right\} \\
k_{\mathrm{t}, \mathrm{p}}= & \frac{k_{\mathrm{ts}}\left[\mathrm{R}_{\mathrm{s}} \cdot\right]_{\mathrm{p}}^{2}}{[\mathrm{R} \cdot]_{\mathrm{p}}^{2}}\left\{1+\frac{k_{\mathrm{tsa}}}{k_{\mathrm{ts}}} \frac{r_{\mathrm{a}}}{r_{\mathrm{s}}} \frac{k_{\mathrm{ps}}}{k_{\mathrm{paa}}} \frac{[\mathrm{AA}]_{\mathrm{p}}}{[\mathrm{S}]_{\mathrm{p}}}\right. \\
& \left.+\frac{k_{\mathrm{taa}}}{k_{\mathrm{ts}}}\left(\frac{r_{\mathrm{a}}}{r_{\mathrm{s}}} \frac{k_{\mathrm{ps}}}{k_{\mathrm{paa}}}\right)^{2}\left(\frac{[\mathrm{AA}]_{\mathrm{p}}}{[\mathrm{S}]_{\mathrm{p}}}\right)^{2}\right\}
\end{aligned}
$$

Where $r_{\mathrm{s}}$ and $r_{\mathrm{a}}$ are the reactivity ratios of styrene and acrylic acid, respectively. Because $k_{\mathrm{pas}}[\mathrm{S}]_{\mathrm{p}} \gg k_{\mathrm{psa}}[\mathrm{AA}]_{\mathrm{p}}$ and $[\mathrm{S}]_{\mathrm{p}} \gg[\mathrm{AA}]_{\mathrm{p}},[\mathrm{S}]_{\mathrm{p}} \approx[\mathrm{M}]_{\mathrm{p}}$, and $\left[\mathrm{R}_{\mathrm{s}} \cdot\right]_{\mathrm{p}} \approx[\mathrm{R} \cdot]_{\mathrm{p}}$ under our experimental conditions. The secondary order terms can be neglected in the brackets of eq 25 and 26 . $2[\mathrm{AA}]_{\mathrm{p}} \ll r_{\mathrm{s}}[\mathrm{S}]_{\mathrm{p}}$ and $k_{\mathrm{tsa}} r_{\mathrm{a}} k_{\mathrm{ps}}[\mathrm{AA}]_{\mathrm{p}} \ll k_{\mathrm{ts}} r_{\mathrm{s}} k_{\mathrm{paa}}[\mathrm{S}]_{\mathrm{p}}$ for the first order terms in the brackets. Under these conditions, taking the logarithms of eq 25 and 26 and rewriting lead to

$$
\begin{gathered}
\ln k_{\mathrm{p}, \mathrm{p}}=\ln k_{\mathrm{ps}}+\frac{2}{r_{\mathrm{s}}[\mathrm{M}]_{\mathrm{p}}}[\mathrm{AA}]_{\mathrm{p}} \\
\ln k_{\mathrm{t}, \mathrm{p}}=\ln k_{\mathrm{ts}}+\frac{r_{\mathrm{a}} k_{\mathrm{tsa}} k_{\mathrm{ps}}}{r_{\mathrm{s}} k_{\mathrm{ts}} k_{\mathrm{paa}}[\mathrm{M}]_{\mathrm{p}}}[\mathrm{AA}]_{\mathrm{p}}
\end{gathered}
$$

When $[\mathrm{S}]_{\mathrm{p}}$ is moles of styrene per liter swollen polymer in polymer particles, $M_{\mathrm{s}}[\mathrm{S}]_{\mathrm{p}}$ and $M_{\mathrm{s}}[\mathrm{S}]_{\mathrm{p}} / \rho_{\mathrm{s}}$ are the weight and volume of styrene per liter swollen polymer. Therefore, the amount of acrylic acid per liter styrene in polymer particles is $[\mathrm{AA}]_{\mathrm{p}} /\left(M_{\mathrm{s}}[\mathrm{S}]_{\mathrm{p}} / \rho_{\mathrm{s}}\right)$. If the solubilities of acrylic acid in styrene of polymer particles and in styrene monomer droplets are the same and $[\mathrm{M}]_{\mathrm{p}} \approx[\mathrm{S}]_{\mathrm{p}}$, then

$$
c_{\text {dist }, \mathrm{a}}=\frac{[\mathrm{AA}]_{\mathrm{p}} /\left(\mathrm{M}_{\mathrm{s}}[\mathrm{M}]_{\mathrm{p}} / \rho_{\mathrm{s}}\right)}{[\mathrm{AA}]_{\mathrm{w}}}
$$

Rearrangement of eq 29 leads to

$$
[\mathrm{AA}]_{\mathrm{p}}=\frac{M_{\mathrm{s}}[\mathrm{M}]_{\mathrm{p}} c_{\mathrm{dist}, \mathrm{a}}}{\rho_{\mathrm{s}}}[\mathrm{AA}]_{\mathrm{w}}
$$

If $A$ in eq 15 is independent of $[\mathrm{AA}]_{\mathrm{w}}$ at small $[\mathrm{AA}]_{\mathrm{w}}$, taking logarithm of eq 15 and combining with eq 16,19 , $20,23,27,28$, and 30 lead to

$$
\ln (S l)=E+F[\mathrm{AA}]_{\mathrm{w}}
$$

where

$$
E=24.00+\ln \left\{\frac{4 \pi}{3} A \frac{k_{\mathrm{ps}}^{2}[\mathrm{M}]_{\mathrm{p}}^{2}}{k_{\mathrm{ts}}}\left(\frac{3 M_{\mathrm{s}}}{4 \pi \rho_{\mathrm{p}}}\right)^{1 / 3}\right\}
$$

$$
\begin{aligned}
& -\frac{2}{3} \ln [\mathrm{S}]_{0} \\
F= & 6.29+\left(\frac{4}{r_{\mathrm{s}}}-\frac{r_{\mathrm{a}} k_{\mathrm{tsa}} k_{\mathrm{ps}}}{r_{\mathrm{s}} k_{\mathrm{ts}} k_{\mathrm{paa}}}\right) \frac{M_{\mathrm{s}} c_{\mathrm{dist}, \mathrm{a}}}{\rho_{\mathrm{s}}} \\
& \left.+\left(\frac{M_{\mathrm{aa}}}{3 M_{\mathrm{s}}}\right)^{1}\right)\left(1+c_{\mathrm{dist}, \mathrm{a}} \frac{W_{\mathrm{s}}}{W_{\mathrm{w}}} \frac{\rho_{\mathrm{w}}}{\rho_{\mathrm{s}}}\right) \frac{1}{[\mathrm{~S}]_{0}}
\end{aligned}
$$

Effect of Acrylic Acid on Radical Penetration Length

Taking the logarithm of eq 9 and combining with eq $16,27,28$, and 30 lead to

$$
\begin{aligned}
\ln L= & 36.00+\ln \left(\frac{2 \pi A^{2} k_{\mathrm{ps}}^{2}[\mathrm{M}]_{\mathrm{p}}^{2}}{\rho_{i} k_{\mathrm{ts}}}\right) \\
& +\left[9.44+\left(\frac{4}{r_{\mathrm{s}}}-\frac{r_{\mathrm{a}} k_{\mathrm{tsa}} k_{\mathrm{ps}}}{r_{\mathrm{s}} k_{\mathrm{ts}} k_{\mathrm{paa}}}\right) \frac{M_{\mathrm{s}} c_{\mathrm{dist}, \mathrm{a}}}{\rho_{\mathrm{s}}}\right][\mathrm{AA}]_{\mathrm{w}}
\end{aligned}
$$

\section{EXPERIMENTAL}

\section{Materials}

Styrene and acrylic acid were distilled twice under reduced pressure prior to polymerization. Potassium persulfate, hydroquinone, and methanol were of analytical grade.

\section{Measurement of Conversion}

Polymerization was carried out in a one liter four-neck glass reactor. The reactor was equipped with a Teflon mixer, thermometer, condenser, and rubber cork for taking samples. Adequate water was added to the reactor and heated to $80 \pm 0.5^{\circ} \mathrm{C}$ in a water bath. After styrene and acrylic acid were added, the mixture was stirred for $15 \mathrm{~min}$. When the aqueous solution containing $1.00 \mathrm{~g}$ potassium persulfate was added, the reaction began. The solution was kept at $80 \pm 0.5^{\circ} \mathrm{C}$ and stirred at $300 \pm$ $20 \mathrm{rpm}$. During the reaction, samples were taken from the reactor. The methanol solution containing excess hydroquinone was added to the sample to stop the reaction, and then water, methanol, and unreacted monomer were evaporated at $50-55^{\circ} \mathrm{C}$. The dried sample was weighed for conversion measurement. The formulas are shown in Table I.

\section{Measurement of Transmission Electron Micrographs}

During the reaction, the sample was taken from the reactor and added to the aqueous solution containing excess hydroquinone. Transmission electron micrographs (TEM) were obtained using a Hitachi electron microscope H-600.

\section{Measurement of $c_{\mathrm{dist}, \mathrm{a}}$}

Adequate acrylic acid and $20 \mathrm{~g}$ styrene were added to

Table I. Formulas of polymerization $\left(80^{\circ} \mathrm{C}\right)$

\begin{tabular}{ccccc}
\hline No. & Styrene $/ \mathrm{g}$ & Acrylic acid $/ \mathrm{g}$ & Water $/ \mathrm{ml}$ & $\mathrm{K}_{2} \mathrm{~S}_{2} \mathrm{O}_{8} / \mathrm{g}$ \\
\hline 1 & 39.654 & 1.156 & 955 & 1.00 \\
2 & 39.654 & 2.012 & 954 & 1.00 \\
3 & 39.700 & 3.029 & 953 & 1.00 \\
4 & 39.725 & 4.044 & 952 & 1.00 \\
5 & 39.857 & 5.064 & 951 & 1.00 \\
\hline
\end{tabular}


$500 \mathrm{ml}$ water. Acrylic acid was added at 0.50 to $3.00 \mathrm{~g}$. The samples were stirred at $80 \pm 0.5^{\circ} \mathrm{C}$ for $30 \mathrm{~min}$ and placed in a water bath. The aqueous solution sample was taken for gas chromatography measurement. The concentration of acrylic acid in aqueous solution was determined from a calibration curve. According to mass balance, the concentration of acrylic acid in styrene phase was calculated. The average value of $c_{\text {dist,a }}$ at $80^{\circ} \mathrm{C}$ is equal to 0.08 from our calculation.

\section{RESULTS AND DISCUSSION}

\section{Effects of Acrylic Acid on Conversion}

Figure 2 shows the conversion curves for several formulas. All curves are concave upward to about $90 \%$ conversion, and then level off. The ultimate conversion decreases from $96 \%$ to $91 \%$ as the content of acrylic acid increases from 1.156 to $5.064 \mathrm{~g}$ per liter solution. The polymerization rate increases with concentration of acrylic acid. A higher concentration of acrylic acid causes larger number density of polymer particles and therefore results in higher polymerization rate.

\section{2/3 Power of Conversion versus Reaction Time}

Figure 3 shows the relations between the 2/3 power of the conversion and reaction time for various formulas. When the conversion is between 0.15 and 0.38 , the $2 / 3$ power of conversion versus reaction time is linear. However, the conversion differs for various formulas. When the conversion is smaller than the lower bound, the data are below the linear fitting line. Two factors affect the polymerization rate. First, the number density of polymer particles decreases with decreasing conversion at the beginning of reaction. Secondly, two radicals cannot be present simultaneously in a polymer particle when the particle size is too small. When conversion is larger than the lower bound, the polymer particle radius is greater than the radical penetration length and eq 14 holds. When the conversion exceeds the upper bound, the data are over the linear fitting line. The larger the conversion, the greater is the deviation. Although $[\mathrm{M}]_{\mathrm{p}}$ in eq 14 decreases with increasing conversion after monomer droplets are depleted, the gel effect counterbalances the



Figure 2. Conversion curves of various formulas, No. 1 , No. 2 O, No $3 \square$, No. $4 \square$, and No. $5 \Delta$ decrease in $[\mathrm{M}]_{\mathrm{p}}$ and causes the polymerization rate to increase effectively. The slopes of the fitting lines are listed in Table III.

\section{Calculation of $A$ in eq 14}

The kinetic rate constants and reactivity ratios at $80^{\circ} \mathrm{C}$ are listed in Table II. The data used to calculate $A$ in eq 14 for various formulas are shown in Table III. When monomer droplets are present in emulsifier-free emulsion polymerization of styrene, the concentration of styrene in polymer particles is about $5.5-5.8 \mathrm{M}$ and an average value of $5.6 \mathrm{M}$ was used. ${ }^{4}$ The densities of styrene and polystyrene are 0.91 and $1.05 \mathrm{~g} \mathrm{ml}^{-1} .^{5}$ From mass balance, the concentration of polymer swollen by monomer in polymer particles, $\rho_{\mathrm{p}}$, is $378 \mathrm{gl}^{-1}$ and the density of polymer particles is $960 \mathrm{gl}^{-1}$ for $[\mathrm{M}]_{\mathrm{p}}=$ $5.6 \mathrm{M}$ in styrene system. Although polymer particles contain acrylic acid in our system, the concentration is very small. The concentation of acrylic acid in aqueous solution is $0.016-0.074 \mathrm{M}$ and $c_{\text {dist,a }}$ is 0.08 in our experiment. The concentration of acrylic acid in polymer particles is smaller than $0.005 \mathrm{M}$. Hence, the effects of acrylic acid on $[\mathrm{M}]_{\mathrm{p}}$, the polymer concentration in polymer particles and the density of polymer particles can be neglected. To calculate the radical generation rate at $80^{\circ} \mathrm{C}, 9.16 \times 10^{-5} \mathrm{~s}^{-1}$, and 0.9 are used for the initiator decomposition rate constant and initiator efficiency, respectively. ${ }^{10}$

Because acrylic acid almost remains in aqueous phase and polymerization reaction proceeds mainly in polymer particles, the change of the concentration of acrylic acid in aqueous solution is neglected in the presence of monomer droplets during shell region polymerization. Consequently, the acrylic acid concentration at the

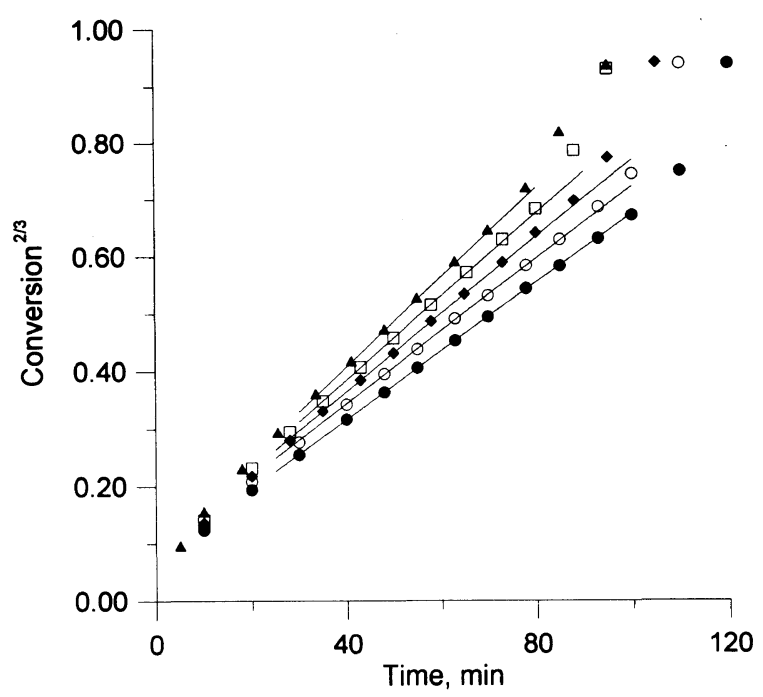

Figure 3. $2 / 3$ power of conversion as a function of reaction time for formulas $1 \bigcirc, 2 \bigcirc, 3 \square, 4 \square$, and $5 \boldsymbol{\Delta}$.

Table II. Kinetic rate constants and reactivity ratios at $80^{\circ} \mathrm{C}$

\begin{tabular}{lccc}
\hline & Styrene & Acrylic acid & Reference \\
\hline$k_{\mathrm{p}} / 1 \mathrm{~mol}^{-1} \mathrm{~s}^{-1}$ & $6.40 \times 10^{2}$ & $5.51 \times 10^{4}$ & 5,6 \\
$k_{\mathrm{t}} / 1 \mathrm{~mol}^{-1} \mathrm{~s}^{-1}$ & $1.03 \times 10^{8}$ & $7.46 \times 10^{7}$ & 5,7 \\
$k_{\mathrm{tab}} / 1 \mathrm{~mol}^{-1} \mathrm{~s}^{-1}$ & $1.43 \times 10^{10}$ & $1.43 \times 10^{10}$ & 8 \\
Reactivity ratio & 0.25 & 0.45 & 9 \\
\hline
\end{tabular}


Table III. Calculation and measurement data at $80^{\circ} \mathrm{C}$

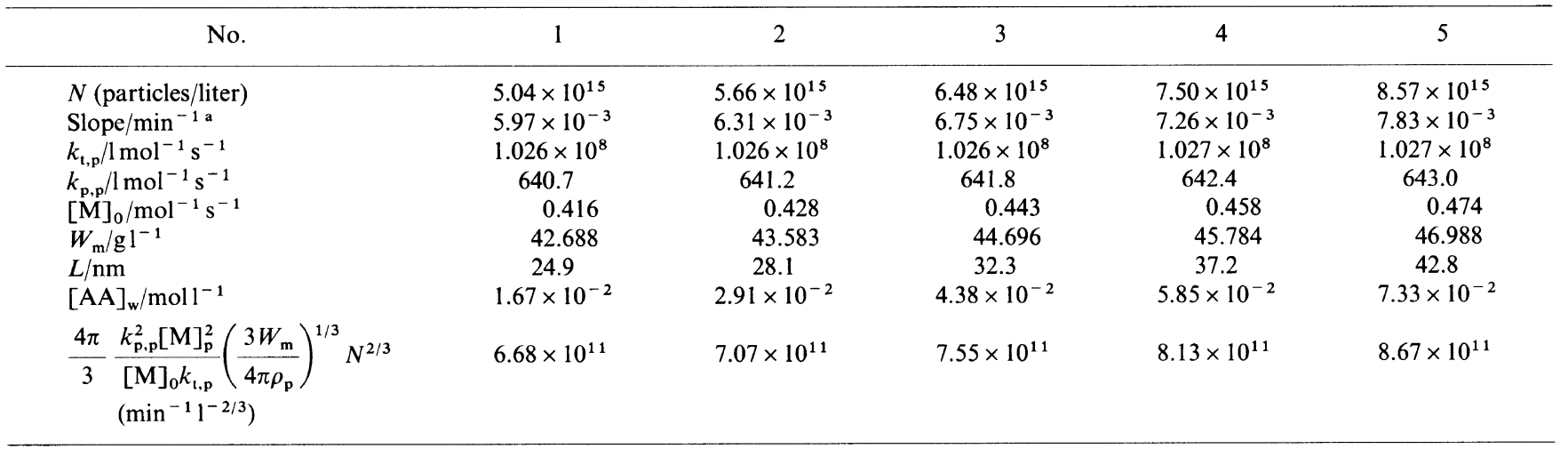

${ }^{\text {a }}$ Slopes were obtained from Figure 3.

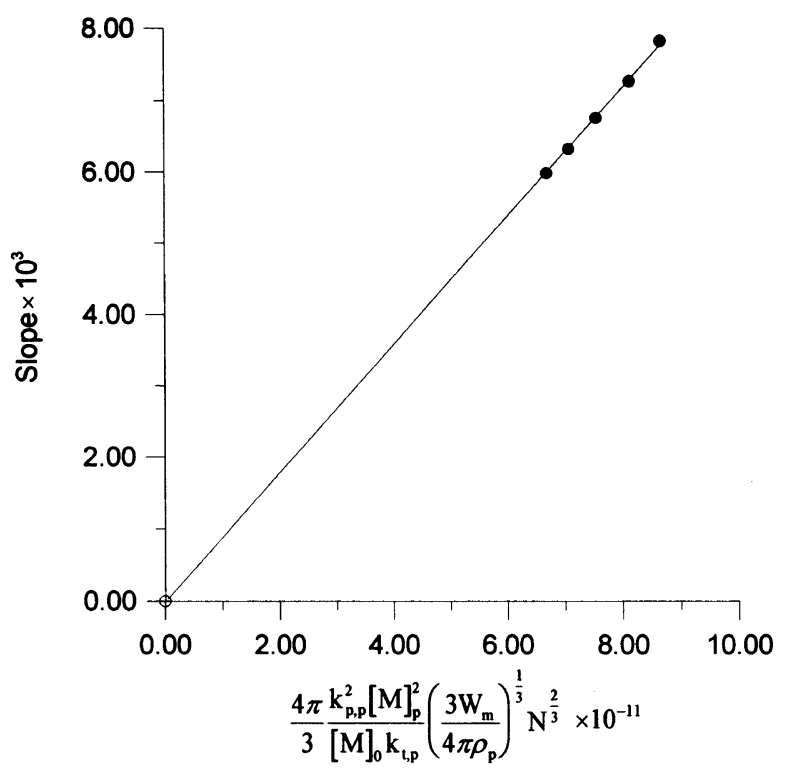

Figure 4. Determination of $A$ from slopes and values of $(4 \pi / 3) \times$ $\left(k_{\mathrm{p}, \mathrm{p}}^{2}[\mathrm{M}]_{\mathrm{p}}^{2} /[\mathrm{M}]_{0} k_{\mathrm{t}, \mathrm{p}}\right)\left(3 W_{\mathrm{m}} / 4 \pi \rho_{\mathrm{p}}\right)^{1 / 3} N^{2 / 3}$ in eq 15 . The slopes are obtained from Figure 3.

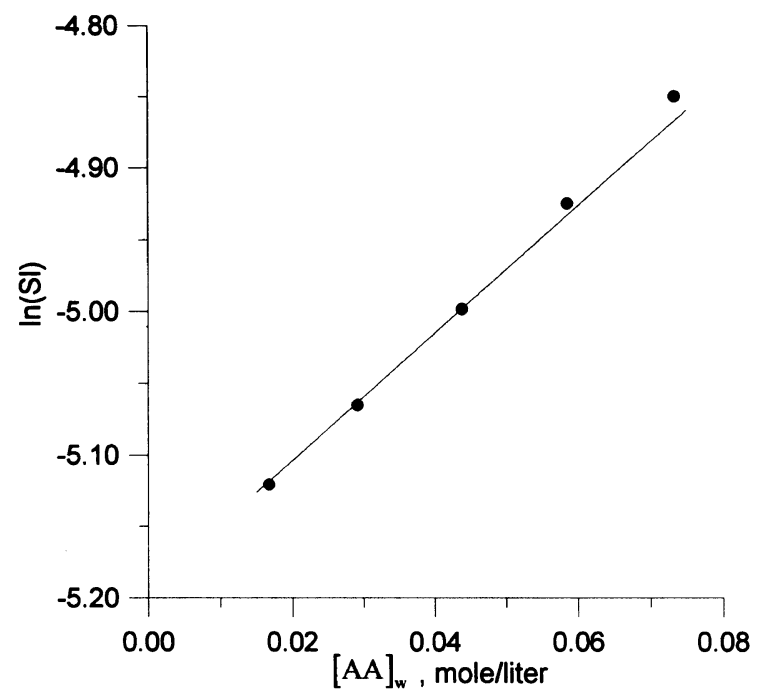

Figure 5. Logarithmic value of slope as a function of concentration of acrylic acid in aqueous solution. The straight line is predicted by eq 31 using the parameters shown in eq 36 and 37 for $E$ and $F$. The points are obtained from Figure 3.

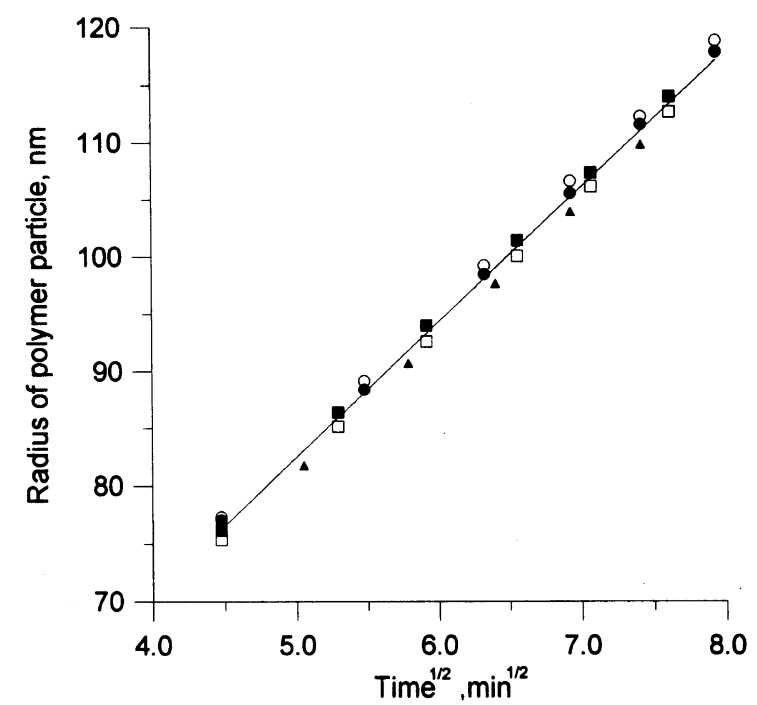

Figure 6. Radius of polymer particle as a function of the square root of reaction time. No $1 \bigcirc$, No $2 \bigcirc$, No. $3 \square$, No. $4 \square$, and No. 5

beginning of reaction can be used for $[\mathrm{AA}]_{\mathrm{w}} \cdot[\mathrm{AA}]_{\mathrm{w}}$, $[\mathrm{AA}]_{\mathrm{p}}, k_{\mathrm{p}, \mathrm{p}}$, and $k_{\mathrm{t}, \mathrm{p}}$ were calculated from eq $22,30,27$, and 28 , respectively.

Figure 4 demonstrates the linear relation between the slopes obtained from Figure 3 and values of

$$
\frac{4 \pi}{3} \frac{k_{\mathrm{p}, \mathrm{p}}^{2}[\mathrm{M}]_{\mathrm{p}}^{2}}{[\mathrm{M}]_{\mathrm{o}} k_{\mathrm{t}, \mathrm{p}}}\left(\frac{3 W_{\mathrm{m}}}{4 \pi \rho_{\mathrm{p}}}\right)^{1 / 3} N^{2 / 3}
$$

This fitting curve is a straight line passing through the original point. $A$ in eq 15 is the slope of the fitting curve, and is equal to $8.96 \times 10^{-15} \mathrm{liter}^{2 / 3}$. Because $A$ is constant, eq 9 shows the radical penetration length in a batch reaction is constant in the presence of monomer droplets during shell region polymerization.

When the radical penetration length is constant, eq 35 can be obtained from eq 5, 10, and 12 .

$$
x^{2 / 3}=\frac{2}{3} \frac{k_{\mathrm{p}, \mathrm{p}}[\mathrm{M}]_{\mathrm{p}}}{[\mathrm{M}]_{0}}\left(\frac{3 W_{\mathrm{m}}}{4 \pi \rho_{\mathrm{p}}}\right)^{1 / 3}\left(\frac{2 \pi \rho_{i} L}{k_{\mathrm{t}, \mathrm{p}}}\right)^{1 / 2} N^{1 / 6} t+b
$$

Insertion of eq 9 into eq 35 yields eq 15 , too.

\section{Comparison of Sl between Experimental Data and Theo- retical Result}

If the unit of $S l$ in eq 15 is $\mathrm{min}^{-1}$, insertion of $A$ and 


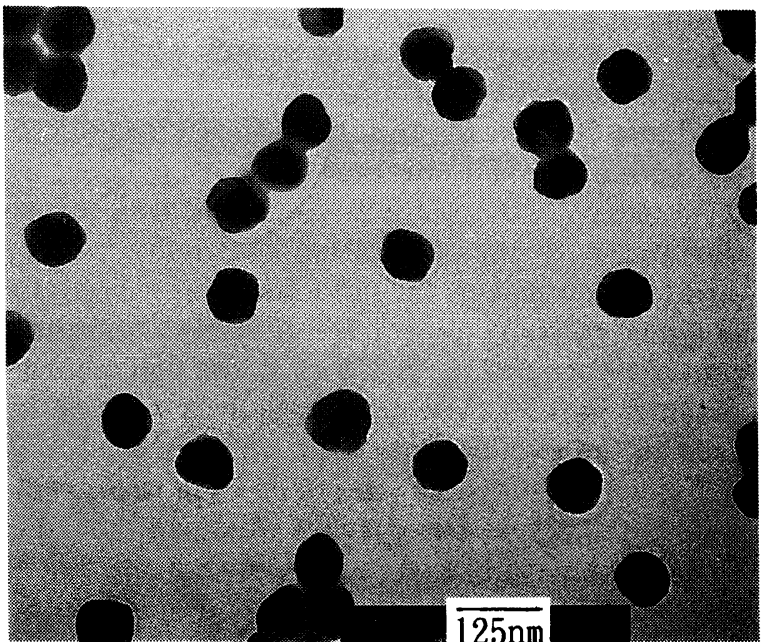

(a) $10 \mathrm{~min}$

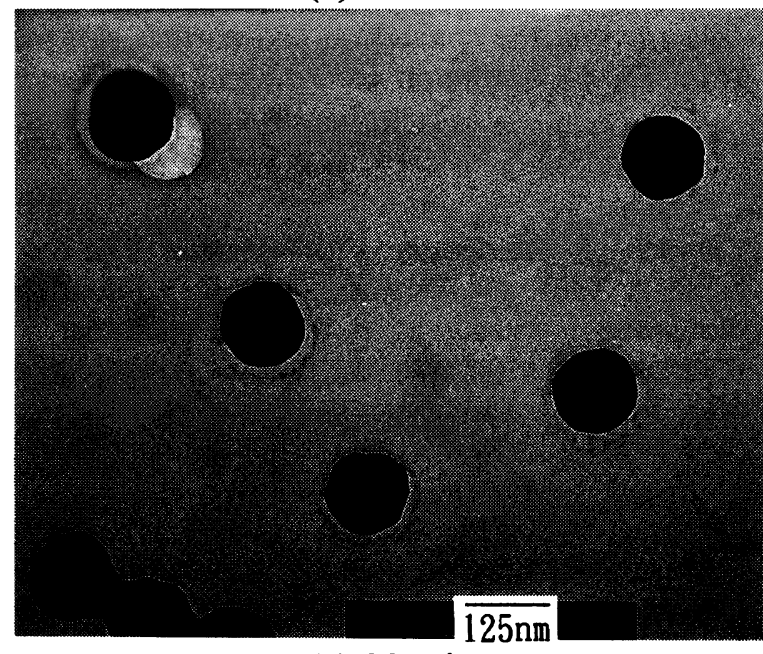

(c) $30 \mathrm{~min}$

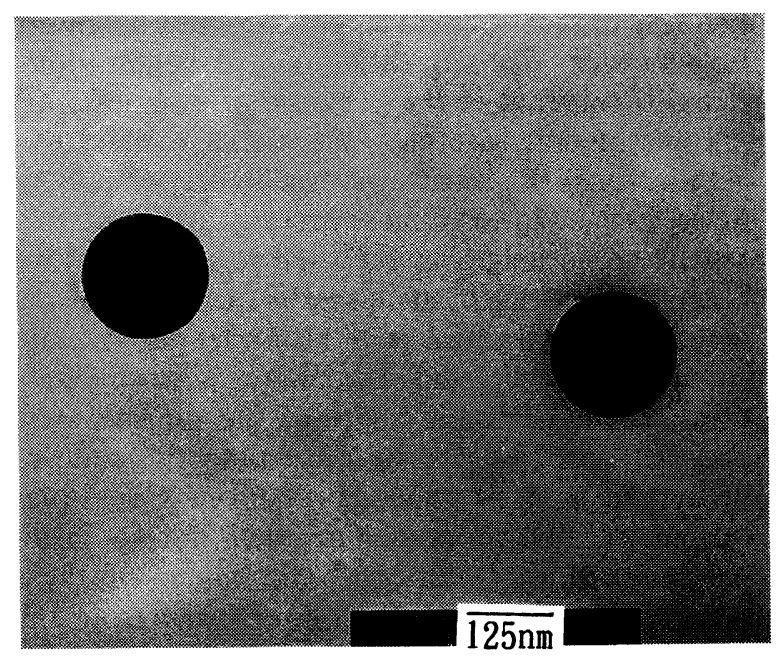

(e) $80 \mathrm{~min}$

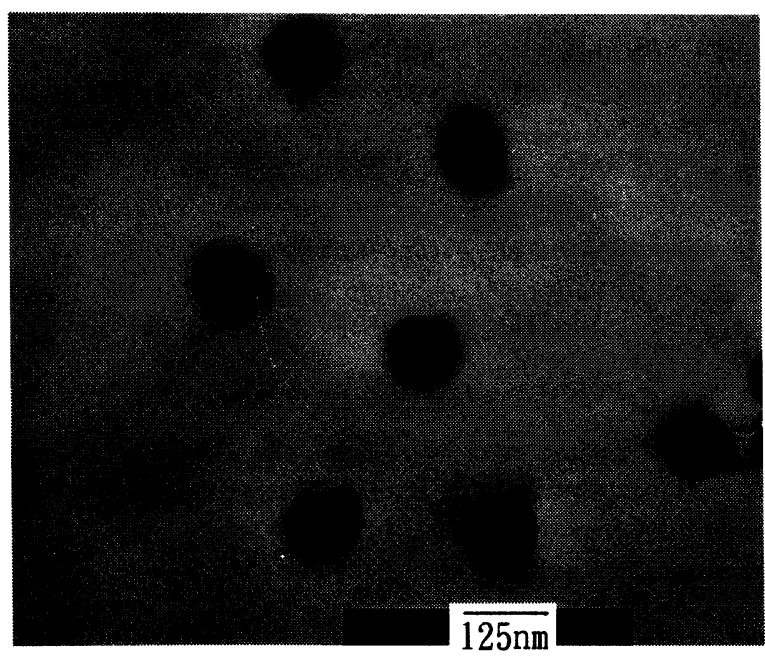

(b) $20 \mathrm{~min}$

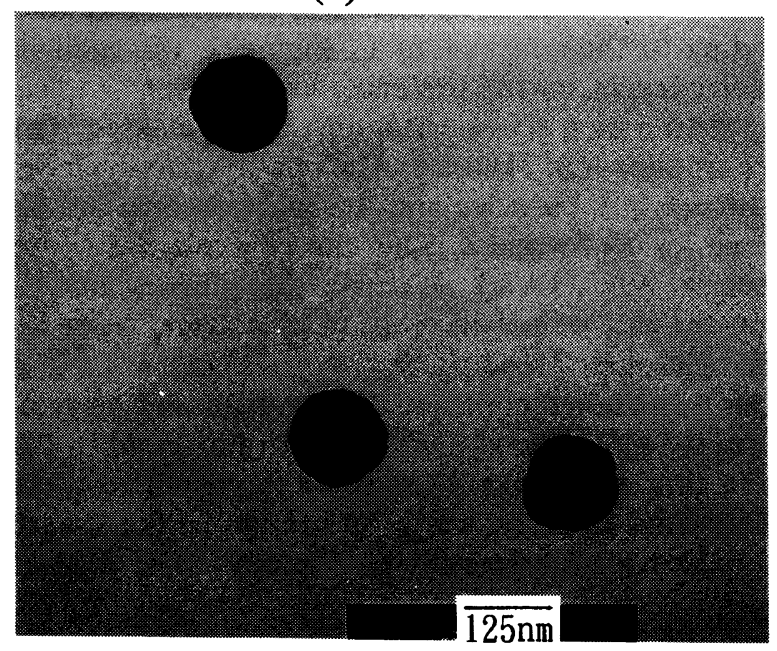

(d) $40 \mathrm{~min}$

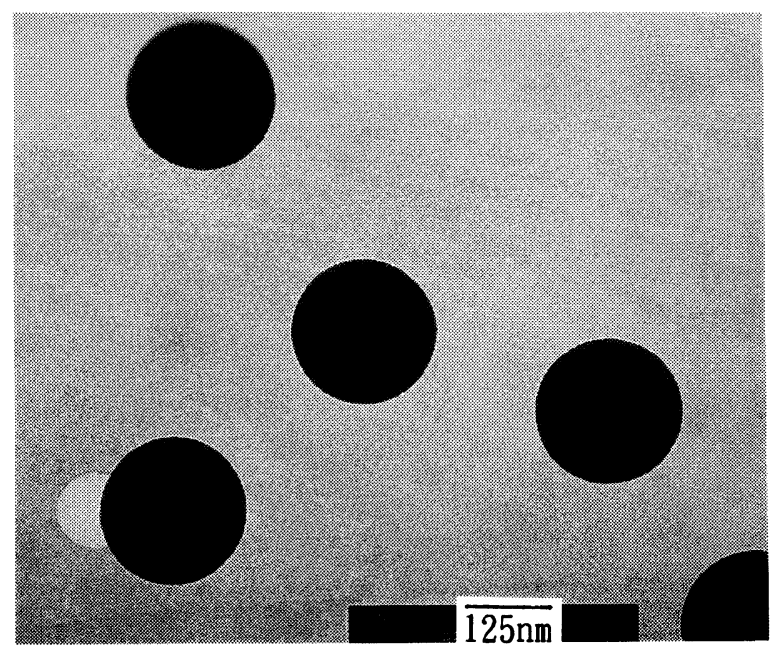

(f) $90 \mathrm{~min}$

Figure 7. TEM micrographs of polymer particles at various reaction times for formula 3. (a) $10 \mathrm{~min}$, (b) $20 \mathrm{~min}$, (c) $30 \mathrm{~min}$, (d) $40 \mathrm{~min}$, (e) $80 \mathrm{~min}$, and (f) $90 \mathrm{~min}$.

characteristic values listed in Table III into eq 32 and 33 yields

$$
E=-5.81-\frac{2}{3} \ln [\mathrm{S}]_{0}
$$

$$
F=6.41-0.77 \frac{1+0.88 \frac{W_{\mathrm{s}}}{W_{\mathrm{w}}}}{[\mathrm{S}]_{0}}
$$

Figure 5 illustrates the relation between $\ln (S l)$ and 
$[\mathrm{AA}]_{\mathrm{w}}$ when the content of acrylic acid in formula is between 1.156 and $5.064 \mathrm{~g}$ per liter solution. The straight line is predicted by eq 31 using the $E$ and $F$ shown in eq 36 and 37. The experimental data are obtained from Figure 3, and consistent with theoretical results.

\section{Radical Penetration Length and Polymer Particle Radius}

If the unit of $L$ in eq 9 is decimeter, insertion of $A$ and characteristic values listed in Table III into eq 34 leads to

$$
\ln L=-15.36+9.56[\mathrm{AA}]_{\mathrm{w}}
$$

The higher the concentration of acrylic acid, the longer is the radical penetration length. Lengths for various formulas are shown in Table III.

The rearrangement of eq 12 yields

$$
r=\left(\frac{3 W_{\mathrm{m}} x}{4 \pi \rho_{\mathrm{p}} N}\right)^{1 / 3}
$$

According to the conversions in Figure 2, the radii of polymer particles in the presence of monomer droplets during shell region polymerization were calculated. The results are shown in Figure 6 . The relations between the radii of polymer particles and the reaction time are all the same for all formulas. This can be explained by eq 14 and 39 . When $[\mathrm{AA}]_{\mathrm{w}}$ is small, the effect of acrylic acid on the rate of polymerization in polymer particles can be neglected. Thus, $\rho_{\mathrm{p}}, k_{\mathrm{p}, \mathrm{p}}, k_{\mathrm{t}, \mathrm{p}},[\mathrm{M}]_{\mathrm{p}},[\mathrm{M}]_{0}$, and $W_{\mathrm{m}}$ can be assumed constant. If $b$ is small and neglected in eq 14 , eq 14 shows $(x / N)^{2 / 3}$ is proportional to the reaction time. Equation 39 shows $r$ is proportional to $(x / N)^{1 / 3}$. Consequently, $r$ is proportional to the square root of the reaction time for all formulas. The data in

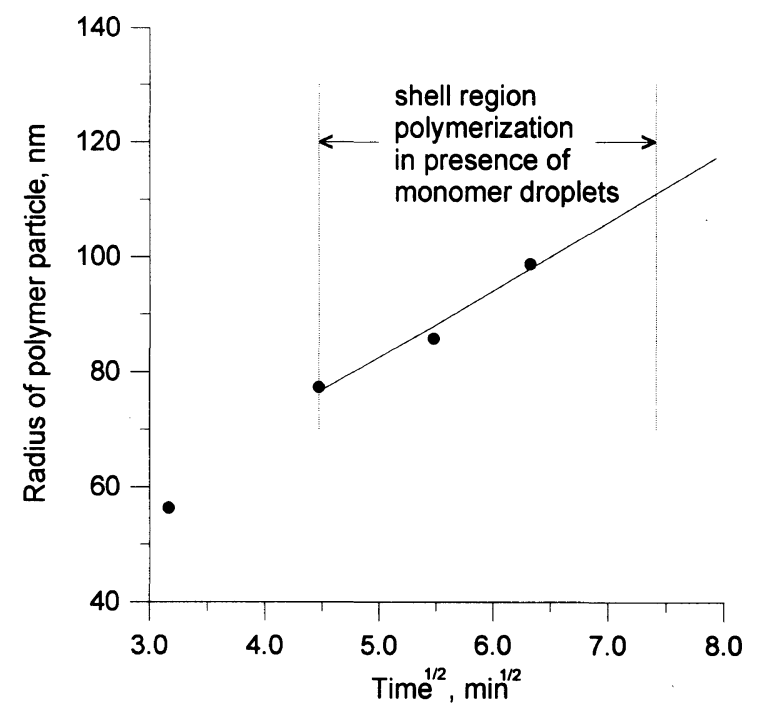

Figure 8. Comparison of radii of polymer particles from conversion and TEM micrographs. The curve is from Figure 6. The data are from TEM micrographs and calibration by volume fraction.
Figure 6 also show polymer particle radius is greater than the radical penetration length when the reaction time is longer than $20 \mathrm{~min}$.

Figure 7 shows the transmission electron micrographs for formula 3 . The average radii of polymer particles were measured from transmission electron micrographs directly. With the application of an electrical beam in TEM measurement, the monomer was evaporated from polymer particles. When the polymer concentration in polymer particles, $\rho_{\mathrm{p}}$, is $378 \mathrm{gl}^{-1}$, the volume fraction of polymer is 0.36 . After calibration by volume fraction, radii in the swollen state were obtained.

Figure 8 compares of polymer particle radii from different sources. The curve is obtained from Figure 6. The data are calibrated radii from transmission electron micrographs. The results show good agreement of data from two methods.

The number density of polymer particles can be calculated from the conversion and particle size measured from TEM micrograph according to eq 40 .

$$
N=\frac{3 W_{\mathrm{m}} x}{4 \pi \rho_{\mathrm{ps}} r^{3}}
$$

where $\rho_{\mathrm{ps}}$ is the density of polystyrene. The results are listed in Table IV for formula 3. By comparison with the number density of polymer particles at 3 hours reaction, $6.48 \times 10^{15} 1^{-1}$, the number density is constant after $20 \mathrm{~min}$ of reaction.

\section{CONCLUSIONS}

During shell region polymerization, the bigger polymer particle supplies the larger space in the shell region for radicals. The larger space causes lower radical concentration, resulting in the longer kinetic chain length. Increase of kinetic chain length is counterbalanced by the larger space. Consequently, radical penetration length remains constant in the presence of monomer droplets.

For different formulas, the higher content of acrylic acid leads to the larger number density of polymer particles, causing lower radical concentration and the longer kinetic chain length in the shell region. The longer the kinetic chain length, the larger is the radical penetration length. Hence, radical penetration length increases with content of acrylic acid. Under our experimental conditions, the logarithmic value of the number density of polymer particles is proportional to the concentration of acrylic acid in aqueous solution. Consequently in the presence of monomer droplets during shell region polymerization, the logarithmic values of the radical penetration length and the slope obtained from $2 / 3$ power of conversion versus reaction time are proportional to acrylic acid concentration.

Table IV. Diameter and number density of polymer particles in formula 3

\begin{tabular}{lcccccc}
\hline \multicolumn{1}{c}{ Time $/$ min } & 10 & 20 & 30 & 40 & 80 & 90 \\
\hline Diameter $/ \mathrm{nm}$ & 80 & 109 & 124 & 141 & 187 & 217 \\
$N$ (particles/liter) & $8.00 \times 10^{15}$ & $6.43 \times 10^{15}$ & $6.88 \times 10^{15}$ & $6.46 \times 10^{15}$ & $6.44 \times 10^{15}$ & $6.49 \times 10^{15}$ \\
\hline
\end{tabular}




\section{REFERENCES}

1. J. Ugelstad and F. K. Hansen, Rubber Chem. Technol., 49, 536 (1976).

2. S.-A. Chen and S.-T. Lee, Macromolecules, 24, 3340 (1991).

3. B.-Z. Yang, L.-W. Chen, and W.-Y. Chiu, "The Effect of Acrylic Acid on Polymer Particle Number Density in Emulsifier-Free Emulsion Copolymerization of Styrene and Acrylic Acid,"

4. Z. Song and G. W. Poehlein, J. Polym. Sci., Polym. Chem. Ed., 28, 2359 (1990).

5. J. Brandrup and E. H. Immergut, "Polymer Handbook," Wiley-Interscience, New York, N. Y., 1989.
6. G. L. Shoaf and G. W. Poehlein, J. Appl. Polym. Sci., 42, 1213 (1991).

7. V. F. Gromov, N. I. Galperina, T. O. Osmanov, P. M. Khomikovskii, and A. D. Abkin, Eur. Polym. J., 16, 529 (1980).

8. G. Odian, "Principles of Polymerization," 3rd ed, p 494, Wiley, New York, N.Y., 1991.

9. H. F. Mark, N. G. Gaylord, and N. M. Bikales, "Encyclopedia of Polymer Science and Technology," Vol 4, Wiley-Interscience, New York, N.Y., 1964, p 203.

10. Z. Song and G. W. Poehlein, J. Colloid Interface Sci., 128, 486 (1989). 